CLINICAL STUDY

\title{
Effects of vitamin D replacement therapy on serum FGF23 concentrations in vitamin D-deficient women in short term
}

\author{
Ayse Kubat Uzum ${ }^{1}$, Serpil Salman ${ }^{1}$, Aysegul Telci ${ }^{2}$, Harika Boztepe ${ }^{1}$, Refik Tanakol ${ }^{1}$, Faruk Alagol $^{1}$ \\ and Nese Colak Ozbey ${ }^{1}$ \\ ${ }^{1}$ Division of Endocrinology and Metabolism, Department of Internal Medicine, Istanbul Faculty of Medicine and ${ }^{2}$ Department of Biochemistry, Istanbul \\ Faculty of Medicine, University of Istanbul, Istanbul 34390, Turkey
}

(Correspondence should be addressed to A Kubat Uzum who is now at Sumer Mah. Prof. Turan Gunes Cad Bausan Veliefendi Evleri, Eren Ap. No: 51 Zeytinburnu/Istanbul, Turkey; Email: akubatuzum@yahoo.com)

\begin{abstract}
Objective: Fibroblast growth factor 23 (FGF23), a phosphatonin, inhibits renal phosphate reabsorption and suppresses 1- $\alpha$ hydroxylase activity. Calcitriol stimulates FGF23 synthesis in bone. We aimed to determine the effect of vitamin D replacement therapy on serum FGF23 concentrations in vitamin Ddeficient women and to compare the FGF23 concentrations of vitamin D-deficient patients with healthy subjects and patients with genetically determined hypophosphatemic rachitis.

Design and methods: The study group was composed of vitamin D-deficient females $(n=18$, mean age $29.1 \pm 9.9$ years), vitamin D-sufficient healthy females (control group; $n=19$, mean age $28.5 \pm 5.2$ years), and patients with genetically determined hypophosphatemic rachitis $(n=13$, mean age 26.5 \pm 15.1 years). The groups were compared for serum FGF23, 1,25-dihydroxyvitamin D3 $(1,25(\mathrm{OH}) 2 \mathrm{D})$, calcium, phosphate, bone turnover markers, intact parathyroid hormone (PTH), and urinary excretion of calcium and phosphate. The vitamin D-deficient group was re-evaluated after a standard treatment regimen.

Results: Serum FGF23 concentrations were significantly lower in vitamin D-deficient patients than in vitamin D-sufficient women and hypophosphatemic rachitis group. Serum FGF23 and phosphate concentrations further decreased significantly during replacement of vitamin $\mathrm{D}(P<0.05)$. A significant negative correlation was evident between FGF23 and PTH before vitamin D replacement in the patients $(r=-0.469, P<0.05)$.

Conclusion: Decreased FGF23 concentrations, which further decline during vitamin D replacement therapy, may have favorable action on bone mineralization by counterregulatory effect on phosphate homeostasis. Lower 1,25(OH)2D concentrations at baseline and hypophosphatemia during treatment may have dominating effects on FGF23 concentrations in vitamin D deficiency, leading to decreased FGF23 concentrations at baseline and during replacement therapy.
\end{abstract}

European Journal of Endocrinology 163 825-831

\section{Introduction}

Studies of several renal phosphate wasting syndromes resulted in the identification of four factors with the predicted characteristics of phosphatonins, which are named as fibroblast growth factor 23 (FGF23), secreted frizzled related protein 4 (SFRP4), matrix extracellular phosphoglycoprotein (MEPE), and FGF-7. The FGF family consists of 22 members for various functions. FGF23 is a peptide released from bone tissue and osteogenic cells (1). FGF23 is a possible phosphatonin and is a $32 \mathrm{kDa}$ (251 amino acids) protein with an $\mathrm{N}$-terminal region that contains the FGF homology domain and a specific 72-amino acid C-terminal fragment (2-5). It is represented as a hormone that acts in embryonic development, cellular differentiation, tissue repair, and tumor growth $(6,7)$.
Although FGF23 may affect kidney, parathyroid gland, and possibly the pituitary gland and choroid plexus, its major target tissue is kidney (8). FGF23 is shown to be phosphaturic. FGF23 suppresses the expression of $\mathrm{Na} / \mathrm{P}_{\mathrm{i}}$-IIIa and $\mathrm{Na} / \mathrm{P}_{\mathrm{i}}$-IIc cotransporters that mediate physiological phosphate uptake in renal proximal tubular epithelial cells. By inhibiting the $\mathrm{Na} / \mathrm{P}_{\mathrm{i}}$-dependent phosphate reabsorption in the proximal tubule, FGF23 can lead to urinary phosphate wasting $(9,10)$. In addition, FGF23 suppresses the expression of 1- $\alpha$ hydroxylase and also enhances the expression of 24-hydroxylase, an enzyme that converts 1,25-dihydroxyvitamin D3 (1,25(OH)2D) into $24,25(\mathrm{OH}) 2 \mathrm{D}$, which is a more hydrophilic metabolite with lesser biological activity. Therefore, bone mineralization reduces $(10,11)$. Systemic factors that regulate serum FGF23 levels are 1,25(OH)2D and 
phosphate. In vivo studies showed a stimulatory effect of 1,25(OH)2D on circulating FGF23 levels (12-14). No increase in FGF23 was observed after 1,25(OH)2D administration in vitamin $\mathrm{D}$ receptor-null mice. This result may support the stimulatory effect of 1,25(OH)2D on serum FGF23 concentrations (12). In addition, increased FGF2 3 concentrations lead to decreased 1- $\alpha$ hydroxylase activity, leading to decreased 1,25(OH)2D production. Parathyroid hormone (PTH) has a stimulatory effect on FGF23 secretion (8).

The hypophosphatemic diseases such as X-linked hypophosphatemia (XLH), autosomal dominant hypophosphatemic rachitis (ADHR), and tumor-induced osteomalacia represent similar clinical and biochemical properties; hypophosphatemia occurs likely due to abnormally low expression of proximal tubular $\mathrm{NaP}_{\mathrm{i}}$-IIa cotransporters, inappropriately low or normal serum 1,25(OH)2D, normal serum calcium and PTH, increased serum phosphatonins such as FGF23, MEPE and SFRP4 levels, and impaired bone mineralization $(7,11,15)$.

It is possible that the resultant increase in serum phosphate concentrations after the administration of 1,25(OH)2D stimulates the release of FGF23, which in turn, reduces serum phosphate by promoting phosphaturia. In hyperphosphatemic states, elevated phosphate and FGF23 concentrations may inhibit 1- $\alpha$ hydroxylase (16).

Although results of studies investigating the mechanism of bone-parathyroid-kidney axis are rising, FGF23 concentrations in vitamin D-deficient patients - in particular - are not examined. In this study, we aimed to determine the effect of vitamin D replacement therapy on serum FGF23 concentrations in vitamin D-deficient patients and to detect the relationships between concentrations of FGF23 and vitamin D metabolites and study parameters. In addition, we aimed to evaluate serum FGF23 concentrations in healthy vitamin D-sufficient subjects and in patients with genetically determined hypophosphatemic rachitis (autosomal dominant/X-linked).

\section{Materials and methods}

\section{Study protocol}

The study group consisted of three groups: vitamin D-deficient premenopausal females (group 1), vitamin D-sufficient healthy premenopausal females (control group-group 2), and patients with hereditary hypophosphatemic rachitis (group 3). Vitamin D-deficient female group was re-evaluated after vitamin D replacement treatment at sixth week.

Group 1 Eighteen premenopausal female patients (mean age $29.1 \pm 9.9$ years) with a diagnosis of vitamin $\mathrm{D}$ deficiency were included in this group. Vitamin D deficiency was diagnosed according to the serum 25 hydroxy vitamin D3 (250HD) concentrations $(<30 \mathrm{ng} / \mathrm{ml})$. Muscle weakness and generalized pain were the major complaints of all patients for admission to the hospital. All the patients in this group were evaluated systematically, no medical diagnosis other than vitamin D deficiency was noted. Reasons for vitamin D deficiency were verified as insufficient exposure to sunlight, frequent parturition, and prolonged lactation. Patients were physically stable, had no abnormal physical examination other than proximal muscle weakness, and took no medication known to affect bone metabolism. All these patients received a standard treatment regimen: vitamin D3 $150000 \mathrm{IU}$ once for all and subsequently $880 \mathrm{IU} \mathrm{D} 3+1000 \mathrm{mg}$ calcium carbonate per day for 6 weeks. This group was also evaluated during replacement therapy at sixth week. Vitamin D deficiency was diagnosed according to the $250 \mathrm{HD}$ concentrations.

Group 2 Nineteen healthy premenopausal women (with a mean age of $28.5 \pm 5.2$ years; range 23-44 years) who had normal levels of serum 250HD $(>30 \mathrm{ng} / \mathrm{ml})$ composed the control group.

Group 3 Thirteen patients with hypophosphatemic rachitis with a mean age of $26.5 \pm 15.1$ years (three ADHR and ten XLH; nine females and four males) were included in this group. All patients were diagnosed during childhood.

\section{Biochemical assays}

Patients and controls attended the Endocrinology Clinic of Internal Medicine Department after an overnight fast of $12 \mathrm{~h}$. The investigation was carried out on outpatient basis. Venous blood was obtained for measurements of creatinine, calcium, phosphate, total protein, albumin, intact PTH (iPTH), alkaline phosphatase (ALP), bone ALP (BALP), 1,25(OH)2D, FGF23 and procollagen type $1 \mathrm{~N}$-terminal propeptide (P1NP), and 24-h urine samples were collected for measuring the daily excretions of calcium, phosphate and creatinine. Serum albumin-corrected calcium concentrations were used for statistical purposes.

Vitamin D status was evaluated by measurements of 250HD levels by HPLC method using RECIPE kit (Munich, Germany). Level of $250 \mathrm{HD}>30 \mathrm{ng} / \mathrm{ml}$ was suggested as normal, $20-30 \mathrm{ng} / \mathrm{ml}$ as vitamin D insufficiency, and $<20 \mathrm{ng} / \mathrm{ml}$ as vitamin D deficiency (17).

Although long half-life ( $\cong 2$ months) of vitamin D3 could not allow us to correctly re-evaluate the vitamin D status of the patients by measuring $250 \mathrm{HD}$ six weeks after replacement, we also measured $250 \mathrm{HD}$ concentrations at this time point to ensure replenishment (18).

Blood samples for measuring BALP, 250HD, 1,25(OH)2D, P1NP, and FGF23 were immediately 
centrifuged after collection and stored at $-80{ }^{\circ} \mathrm{C}$ until assay. All other parameters were measured on the same day of collection. All biochemical analyses included measurements of creatinine, calcium, phosphate, total protein, albumin, and ALP on an autoanalyzer, Roche Modular System, D and P modules (Roche Diagnostics) using colorimetric methods, in the Central Laboratory of Biochemistry. iPTH concentrations were measured by electrochemiluminescence on Roche Modular System, E170 module (Roche Diagnostics).

Plasma FGF23 concentrations were measured by a commercial ELISA kit (Immutopics, Inc., San Clemente, CA, USA). The sensitivity of the assay, as determined by the $95 \%$ confidence limit on 20 duplicate determinations of the $0 \mathrm{pg} / \mathrm{ml}$ standard, was $1.0 \mathrm{pg} / \mathrm{ml}$, and the intra-assay coefficient of variation was $4.4 \%$.

Serum 1,25(OH)2D concentrations were measured by a commercial ELISA kit (Immunodiagnostic Systems (IDS) Ltd, Frankfurt, Germany). The sensitivity, defined as the concentration corresponding to the mean -2 s.D. of 20 replicates of the zero calibrator, was $6 \mathrm{pmol} / \mathrm{l}$ $(2.5 \mathrm{pg} / \mathrm{ml})$, and the intra-assay variability was $9.3 \%$.

Serum BALP concentrations were measured by a commercial immunoenzymetric assay kit (Ostease BAP, Immunodiagnostic Systems (IDS) Ltd). Reference interval was 11.6-29.6 U/l for women 18-44 years of age and 14.2-42.7 U/l for women older than 45 years. Intra- and inter-assay coefficients of variation were 2.6 and $3.7 \%$ respectively.

Serum P1NP concentrations were measured using RIA (Orion Diagnostica, Espoo, Finland). Reference interval was $19-83 \mu \mathrm{g} / \mathrm{l}$ for premenopausal women and $16-103 \mu \mathrm{g} / \mathrm{l}$ for postmenopausal women. Intraand inter-assay coefficients of variation were 6.5 and $6.0 \%$ respectively.

Tubular maximum for phosphate corrected for glomerular filtration rate (TmP/GFR) is a factor independent of plasma phosphate and renal functions for assessment of renal phosphate handling. TmP/GFR is an index of renal threshold for phosphate with a normal range of $2.8-4.4 \mathrm{mg} / \mathrm{dl}$ and is calculated with a previously validated formula (19):

$\mathrm{TmP} / \mathrm{GFR}=\mathrm{P}$ phosphate $-\left(\frac{\mathrm{U} \text { phosphate } \times \mathrm{P} \text { creatinine }}{\mathrm{U} \text { creatinine }}\right)$

where $\mathrm{P}$ is plasma and $\mathrm{U}$ is urine.

The protocol was approved by the ethics committee of the Istanbul University, Istanbul Faculty of Medicine, and written informed consent was obtained from each subject. The present work was supported by the Research Fund of Istanbul University (Project No:573/05052006).

\section{Statistical analyses}

All statistical analyses were performed with SPSS v 11.0 (SPSS, Chicago, IL, USA). Descriptive statistical results are presented in the tables as the means \pm s.D. Some of the study parameters significantly deviated from a normal distribution (creatinine, PTH, FGF23, BALP, and P1NP), by Kolmogorov-Smirnov test. Therefore, logarithmic transformations were applied for these parameters.

Kruskal-Wallis test was performed for ANOVA. For comparisons between the groups, Student's $t$-test was used. Comparisons between the patients at baseline and after the treatment were determined by paired $t$-test. Pearson correlation analysis was used to detect significant univariate relationships between the serum FGF23 levels and study parameters. All the tests were two sided, and a $P$ value $<0.05$ was considered as significant.

\section{Results}

The study parameters of the groups are given in Table 1 . In group 1 , mean $250 \mathrm{HD}$ concentration was 8.0 $\pm 4.2 \mathrm{ng} / \mathrm{ml}$. Twelve of the patients had 250HD concentrations $<10 \mathrm{ng} / \mathrm{ml}$; six of them had $250 \mathrm{HD}$ concentrations between 10 and $20 \mathrm{ng} / \mathrm{ml}$. After the standard treatment regimen, serum $250 \mathrm{HD}$ concentration of group 1 increased to $15.1 \pm 6.1 \mathrm{ng} / \mathrm{ml}$ at sixth week. Serum calcium, 1,25(OH)2D, and FGF2 3 concentrations were significantly lower, whereas serum PTH, ALP, and BALP concentrations were significantly higher in vitamin D-deficient patients (group 1) than in healthy women.

Group 3 comprised of 13 patients with genetically determined hypophosphatemic rachitis. Ten of thirteen patients were XLH and the members of the same family, and the others were ADHR. The highest mean serum FGF23 and lowest mean TmP/GFR levels were detected in this group. Only 4 of 13 patients were on calcitriol and oral phosphate treatment. In the treated group, serum FGF23 concentration was non-significantly lower than in the untreated patients (data not shown).

Biochemical changes in group 1 with administration of vitamin D and calcium are given in Table 2 (and Fig. 1). After vitamin D3 + calcium replacement, serum calcium, 250HD, 1,25(OH)2D concentrations and urinary calcium excretion were significantly increased, while serum phosphorus, iPTH, ALP, BALP, and P1NP concentrations were significantly decreased. Also we found a significant decrease in serum FGF23 concentrations after replacement therapy. Urinary phosphate excretion and TmP/GFR did not differ significantly before and after replacement therapy.

Control group and group 1 data before and after vitamin D replacement were analyzed separately and together to detect possible correlations between FGF23 concentrations and study parameters. A significant positive correlation was found between FGF23 and serum calcium concentrations in pre-/post-treatment groups and in combined group. In patients of group 1 , 
Table 1 Comparison of biochemical parameters (mean \pm s.D.) between vitamin D-deficient patients before treatment, patients with genetically determined hypophosphatemic rachitis and the control group.

\begin{tabular}{|c|c|c|c|}
\hline & $\begin{array}{c}\text { Vitamin D-deficient } \\
\text { patients (before treatment) } \\
(n=18)\end{array}$ & $\begin{array}{c}\text { Patients with genetically } \\
\text { determined hypophosphatemic } \\
\text { rachitis }(n=13)\end{array}$ & $\begin{array}{l}\text { Control healthy } \\
\text { subjects }(n=19)\end{array}$ \\
\hline Age & $29.1 \pm 9.9$ & $26.5 \pm 15.1$ & $28.5 \pm 5.2$ \\
\hline Corrected calcium (mg/dl) & $8.9 \pm 0.3^{\dagger}$ & $8.8 \pm 0.1^{\ddagger}$ & $9.2 \pm 0.3$ \\
\hline Serum phosphate (mg/dl) & $3.9 \pm 0.6^{\S}$ & $2.1 \pm 0.2^{*}$ & $3.9 \pm 0.3$ \\
\hline Serum creatinine $(\mathrm{mg} / \mathrm{dll})^{\mathrm{a}}$ & $0.6 \pm 0.1^{\top}$ & $0.8 \pm 0.1$ & $0.7 \pm 0.1$ \\
\hline Serum iPTH $(\mathrm{pg} / \mathrm{ml})^{\mathrm{a}}$ & $80.3 \pm 52.5^{\dagger}$ & $77.8 \pm 8.8^{\ddagger}$ & $37.8 \pm 6.6$ \\
\hline Serum 25(OH)D (ng/ml) & $8.0 \pm 4.2^{*, \|}$ & $24.1 \pm 5.6^{\dagger}$ & $39.2 \pm 19.1$ \\
\hline Serum $1,25(\mathrm{OH}) 2 \mathrm{D}(\mathrm{pmol} / \mathrm{l})$ & $47.0 \pm 14.9^{\dagger}$ & $58.7 \pm 27.3$ & $73.3 \pm 30.3$ \\
\hline Serum ALP $(\mathrm{U} / \mathrm{I})$ & $220.2 \pm 161.6^{\dagger}$ & $268.6 \pm 36.2^{\ddagger}$ & $112.3 \pm 47.9$ \\
\hline Serum BALP $(U / I)^{a}$ & $29.0 \pm 29.9^{ \pm, 9}$ & $43.0 \pm 24.6^{*}$ & $10.7 \pm 16.1$ \\
\hline Urine calcium (mg/day) & $136.2 \pm 79.1^{\star, \S}$ & $701.3 \pm 389.2^{*}$ & $201.2 \pm 42.5$ \\
\hline Urine phosphate (mg/day) & $0.4 \pm 0.2$ & $0.9 \pm 0.7$ & $0.7 \pm 0.1$ \\
\hline P1NP $(\mu \mathrm{g} /)^{\mathrm{a}}$ & $89.4 \pm 66.8$ & $145.9 \pm 115.0^{\dagger}$ & $46.6 \pm 25.5$ \\
\hline Serum FGF23 $(\mathrm{pg} / \mathrm{ml})^{\mathrm{a}}$ & $23.4 \pm 19.4^{\ddagger, \S}$ & $172.4 \pm 228.1^{\dagger}$ & $36.7 \pm 23.3$ \\
\hline TmP/GFR (mg/dl) & $3.2 \pm 0.3^{\|}$ & $0.98 \pm 0.6^{\ddagger}$ & $3.1 \pm 0.5$ \\
\hline
\end{tabular}

${ }^{\star} P<0.001,{ }^{\dagger} P<0.01,{ }^{\ddagger} P<0.05$ when compared with healthy control subjects. ${ }^{\S} P<0.001, "{ }^{\|} P<0.01,{ }^{\circledR} P<0.05$ when compared with patients with genetically determined hypophosphatemic rachitis.

${ }^{a}$ Parameters deviated from normal distribution by Kolmogorov-Smirnov test. Significant differences were determined by Kruskal-Wallis test.

FGF23 showed significant negative correlation with PTH before vitamin D replacement. In the control group, FGF23 was positively correlated with age and P1NP (Table 3). Serum 25OHD concentrations correlated significantly and positively with $1,25(\mathrm{OH}) 2 \mathrm{D}$ concentrations before treatment and in the combined pre- and post-treatment group $(r=0.598, P=0.009$; $r=0.494, P=0.009$ respectively).

\section{Discussion}

The main findings of this study are as follows: i) FGF23 concentrations are significantly lower in vitamin D-deficient women than in vitamin D-sufficient healthy women, ii) FGF23 concentrations decreases after vitamin $\mathrm{D}$ replacement therapy in vitamin D-deficient otherwise healthy women. In addition, a significant negative correlation was evident between FGF23 and
PTH concentrations in vitamin D-deficient women at baseline. Measurement of plasma FGF2 3 concentrations by ELISA helps to detect increased FGF23 concentrations in association with genetically determined hypophosphatemic disorders.

Relationship between 1,25(OH)2D concentration and FGF23 synthesis was obtained from animal models. 1,25(OH)2D was observed to up-regulate FGF23 gene expression in bone $(1,13,20)$. Liu et al. (13) reported that calcitriol stimulates FGF23 synthesis in bone, and FGF23 may act as a counterregulatory phosphaturic hormone to maintain phosphate homeostasis in response to vitamin D. Decreased FGF23 concentrations in vitamin D-deficient women at baseline in this study could be explained by the lower $1,25(\mathrm{OH}) 2 \mathrm{D}$ concentrations leading to decreased FGF23 synthesis in bone. Extracellular phosphate induces FGF23 mRNA expression in osteoblast-like cells (21). In vitamin D deficiency states, decreased serum phosphate

Table 2 Serum FGF23 concentrations and biochemical parameters (mean \pm s.D.) before and 6 weeks after a standard treatment regimen.

\begin{tabular}{|c|c|c|c|}
\hline & Before treatment & After treatment at sixth week & $\boldsymbol{P}$ \\
\hline Corrected calcium (mg/dl) & $8.9 \pm 0.3$ & $9.3 \pm 0.3$ & $<0.001$ \\
\hline Serum phosphate (mg/dl) & $3.9 \pm 0.6$ & $3.6 \pm 0.2$ & 0.047 \\
\hline Serum creatinine $(\mathrm{mg} / \mathrm{dl})$ & $0.6 \pm 0.1$ & $0.7 \pm 0.1$ & NS \\
\hline Serum iPTH (pg/ml) & $80.3 \pm 52.5$ & $46.1 \pm 14.5$ & 0.003 \\
\hline Serum 25OHD (ng/ml) & $8.0 \pm 4.2$ & $15.1 \pm 6.1$ & 0.005 \\
\hline Serum 1,25(OH)2D (pmol/l) & $47.0 \pm 14.9$ & $93.9 \pm 31.5$ & 0.001 \\
\hline Serum ALP (U/I) & $220.2 \pm 161.6$ & $159.8 \pm 102.0$ & 0.024 \\
\hline Serum BALP (U/I) & $29.0 \pm 29.9$ & $18.7 \pm 20.1$ & 0.049 \\
\hline Urine calcium (mg/day) & $136.2 \pm 79.1$ & $292.0 \pm 146.8$ & 0.019 \\
\hline Urine phosphate (mg/day) & $0.4 \pm 0.2$ & $0.7 \pm 0.2$ & NS \\
\hline P1NP $(\mu \mathrm{g} / \mathrm{l})$ & $89.4 \pm 66.8$ & $73.8 \pm 64.7$ & 0.003 \\
\hline Serum FGF23 (pg/ml) & $23.4 \pm 19.4$ & $15.6 \pm 12.5$ & 0.04 \\
\hline TmP/GFR (mg/dl) & $3.2 \pm 0.3$ & $3.1 \pm 0.4$ & NS \\
\hline
\end{tabular}

Significant values are presented in boldface. 


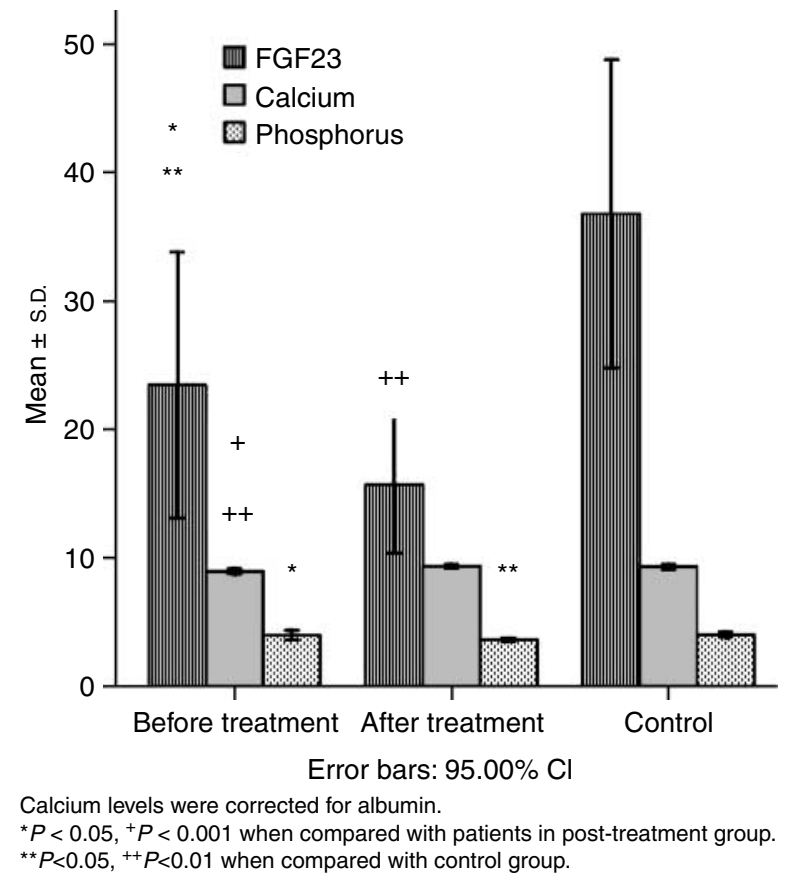

Figure 1 Mean \pm S.D. of serum FGF23, calcium, and phosphorus concentrations in patients with vitamin $\mathrm{D}$ deficiency (before and after vitamin $\mathrm{D}+$ calcium replacement) and in healthy control subjects.

concentrations may also lead to decreased FGF23 synthesis in bone at baseline. But our vitamin D-deficient patients have phosphate concentrations similar to controls at baseline. FGF23 is known to inhibit 1- $\alpha$ hydroxylase activity leading to decreased $1,25(\mathrm{OH}) 2 \mathrm{D}$ concentrations. This may indirectly stimulate PTH synthesis. In addition FGF23 is reported to directly influence parathyroid gland, leading to decreased PTH synthesis and secretion (22). Resistance to inhibitory action of FGF23 on PTH secretion is reported in patients with chronic renal failure and suggested to have a role in secondary hyperparathyroidism of chronic renal failure (23). These associations may explain the significant negative correlation between PTH and FGF23 in vitamin D-deficient patients in this study, i.e. decreased FGF23 concentrations in vitamin $\mathrm{D}$ deficiency contribute to increased PTH concentrations. Although decreased
FGF23 concentrations may lead to increased PTH secretion, increased PTH could lead to suppression of FGF23 synthesis/secretion by osteoblasts. However, an animal primary hyperparathyroidism model (PTH-cyclin D1 transgenic mice) indicates increased FGF23 concentrations, which decrease after parathyroidectomy. It is suggested that PTH plays a major role in FGF23 levels in primary hyperparathyroidism by osteoblast activation (24). In vitamin D deficiencyinduced secondary hyperparathyroidism, the effects of increased PTH concentrations on FGF23 synthesis by bone cells should be different. In our patients, vitamin D treatment decreased FGF23 concentrations further. At sixth week, FGF23 concentrations of vitamin D-treated patients were significantly lower than those of patients before treatment and normal subjects. Although a longer follow-up period is needed to detect sequential changes of FGF23 concentrations after vitamin D treatment, we suggest that in vitamin $\mathrm{D}$ deficiency, the effects of lower 1,25(OH)2D on FGF23 concentrations dominate, leading to decreased FGF23 concentrations at baseline. However, after replacement therapy, FGF23 concentrations further decline, suggesting the dominating effect of decreased serum phosphate concentrations. In our vitamin D-deficient patients, serum phosphate concentrations decreased during replacement. Vitamin D increases intestinal calcium and phosphate absorption (17). Decreased serum phosphate concentrations in association with increased calcium, decreased PTH, and increased 1,25(OH)2D concentrations during vitamin D replacement therapy may reflect the deposition of calcium and phosphate in bone during the healing process. A previous study indicating the effects of vitamin D replacement therapy in elderly showed that at week 12 , serum phosphate concentration increased significantly compared with that at week 0 . At week 2 , a decline in serum phosphate concentrations was evident, although elderly patients had probably reduced urinary phosphate excretion because of decreased GFR (25). In our vitamin D-deficient patients, decreased FGF23 concentrations at baseline and during treatment may lead to decreased phosphate excretion by the kidney and have a counterregulatory effect on hypophosphatemia at baseline and during follow-up. Decreased FGF23 concentrations may hasten bone healing during vitamin $\mathrm{D}$ treatment.

Table 3 Significant correlations between FGF23 concentrations and study parameters in vitamin D-deficient patients (pre-treatment, post-treatment, combined pre- and post-treatment) and in healthy control subjects.

\begin{tabular}{|c|c|c|c|c|c|c|c|c|}
\hline & \multicolumn{2}{|c|}{$\begin{array}{l}\text { Pre-treatment } \\
\text { patients }\end{array}$} & \multicolumn{2}{|c|}{$\begin{array}{l}\text { Post-treatment patients } \\
\text { at sixth week }\end{array}$} & \multicolumn{2}{|c|}{$\begin{array}{l}\text { Combined pre- and } \\
\text { post-treatment patients }\end{array}$} & \multicolumn{2}{|c|}{$\begin{array}{l}\text { Healthy control } \\
\text { subjects }\end{array}$} \\
\hline & $r$ & $P$ & $r$ & $P$ & $r$ & $P$ & $r$ & $P$ \\
\hline $\begin{array}{l}\text { FGF23 } \\
\text { Age } \\
\text { Serum calcium } \\
\text { PTH } \\
\text { P1NP }\end{array}$ & $\begin{array}{r}0.507 \\
-0.469\end{array}$ & $\begin{array}{l}0.03 \\
0.049\end{array}$ & 0.596 & 0.009 & 0.343 & 0.04 & 0.897 & 0.000 \\
\hline
\end{tabular}


A previous study in XLH indicates that treatment with calcitriol and oral phosphate further increased FGF23 concentrations (26). Increased FGF23 concentrations after treatment may further worsen bone healing in osteomalacia leading to further loss of phosphate by kidney.

In our healthy control group, significant positive associations were observed between FGF23 and age and $\mathrm{P} 1 \mathrm{NP}$, an osteoclast marker. In patients, serum calcium concentrations correlated significantly and positively with FGF23 both before and during treatment. Increased FGF23 concentrations during aging may reflect the decreased renal phosphate clearance due to aginginduced decrease in GFR. Vitamin D increases both osteoclast differentiation and FGF23 synthesis by osteoblasts (1). Correlation between FGF23 and P1NP may reflect the effects of calcitriol in bone in healthy subjects.

In conclusion, we suggest that decreased FGF23 concentrations, which further decline during vitamin D replacement therapy, have favorable action on bone mineralization by opposing effect on hypophosphatemia. Although several regulatory factors are identified for FGF23 synthesis and secretion, decreased 1,25(OH)2D concentrations and hypophosphatemia may predominate in vitamin D deficiency states, leading to decreased FGF23 concentrations at baseline and during vitamin D replacement therapy. Further studies are needed to determine the sequential changes of FGF23 concentrations during vitamin D replacement therapy in vitamin D-deficient patients and reveal clinical consequences of decreased FGF23 concentrations.

\section{Declaration of interest}

The authors declare that there is no conflict of interest that could be perceived as prejudicing the impartiality of the research reported.

\section{Funding}

We confirm that this work was supported by Research Fund of the Istanbul University (project number 573).

\section{Author contribution statement}

We also confirm that all of the named authors contributed substantially to the article and agree to take public responsibility for the validity of its content.

\section{Acknowledgements}

Some results of this study is submitted as an abstract to 11th European Congress of Endocrinology (ECE) which was held at Istanbul on 25-29 April 2009.

\section{References}

1 Masuyama R, Stockmans I, Torrekens S, Looveren RV, Maes C, Carmeliet P, Boullion R \& Carmeliet G. Vitamin D receptor in chondrocytes promotes osteoclastogenesis and regulates FGF23 production in osteoblasts. Journal of Clinical Investigation 2006116 3150-3159. (doi:10.1172/JCI29463)
2 The ADHR Consortium. Autosomal dominant hypophosphataemic rickets is associated with mutations in FGF23. Nature Genetics 200026 345-348. (doi:10.1038/81664)

3 Shimada T, Mizutani S, Muto T, Yoneya T, Hino R, Takeda S, Takeuchi Y, Fujita T, Fukumoto S \& Yamashita T. Cloning and characterization of FGF23 as a causative factor of tumor-induced osteomalacia. PNAS 200198 6500-6505. (doi:10.1073/pnas. 101545198)

4 Berndt TJ, Schiavi S \& Kumar R. "Phosphatonins" and the regulation of phosphorus homeostasis. American Journal of Physiology. Renal Physiology 2005289 1170-1182. (doi:10. 1152/ajprenal.00072.2005)

5 Yamashita H, Yamazaki Y, Hasegawa H, Yamashita T, Fukumoto S, Shigematsu T, Kazama JJ, Fukagawa M \& Noguchi S. Fibroblast growth factor-23 in patients with Graves' disease before and after antithyroid therapy: its important role in serum phosphate regulation. Journal of Clinical Endocrinology and Metabolism 200590 4211-4215. (doi:10.1210/jc.2004-2498)

6 Medici D, Razzaque MS, Deluca S, Rector TL, Hou B, Kang K, Goetz R, Mohammadi M, Kuro-O M, Olsen BR \& Lanske B. FGF-23-Klotho signaling stimulates proliferation and prevents vitamin D-induced apoptosis. Journal of Cell Biology 2008182 459-465. (doi:10.1083/jcb.200803024)

7 Perwad F, Zhang MY, Tenenhouse HS \& Portale AA. Fibroblast growth factor 23 impairs phosphorus and vitamin D metabolism in vivo and suppresses 25-hydroxyvitamin D-1alpha-hydroxylase expression in vitro. American Journal of Physiology. Renal Physiology 2007293 F1577-F1583. (doi:10.1152/ajprenal.00463.2006)

8 Ramon I, Kleynen P, Body JJ \& Karmali R. Fibroblast growth factor 23 and its role in phosphate homeostasis. European Journal of Endocrinology 2010162 1-10. (doi:10.1530/EJE-09-0597)

9 Saito H, Kusano K, Kinosaki M, Ito H, Hirata M, Segawa H, Miyamoto K-I \& Fukushima N. Human fibroblast growth factor-23 mutants suppress NaC-dependent phosphate co-transport activity and 1a,25-dihydroxyvitamin D3 production. Journal of Biological Chemistry 2003278 2206-2211. (doi:10.1074/jbc. M207872200)

10 Shimada T, Kakitani M, Yamazaki Y, Hasegawa H, Takeuchi Y, Fujita T, Fukumoto S, Tomizuka K \& Yamashita T. Targeted ablation of FGF23 demonstrates an essential physiological role of Fgf23 in phosphate and vitamin D metabolism. Journal of Clinical Investigation 2004113 561-568. (doi:10.1172/JCI200419081)

11 Bringhurst FR \& Leder BZ. Regulation of calcium and phosphate homeostasis. In Endocrinology, 5th edn, pp 1465-1498. Eds LJ De Groot \& JL Jameson. Philadelphia: Elsevier Saunders, 2006.

12 Saito H, Maeda A, Ohtomo S-I, Hirata M, Kusano K, Kato S, Ogata E, Segawa H, Miyamoto KI \& Fukushima N. Circulating FGF-23 is regulated by 1a,25-dihydroxyvitamin D3 and phosphorus in vivo. Journal of Biological Chemistry 2005280 2543-2549. (doi:10.1074/jbc.M408903200)

13 Liu S, Tang W, Jianping Z, Stubbs JR, Luo Q, Pi M \& Quarles LD. Fibroblast growth factor 23 is a counter-regulatory phosphaturic hormone for vitamin D. Journal of the American Society of Nephrology 200617 1305-1315. (doi:10.1681/ASN. 2005111185)

14 Collins MT, Lindsay JR, Jain A, Kelly MH, Cutler CM, Weinstein LS, Liu J, Fedarko NS \& Winer KK. Fibroblast growth factor-23 is regulated by 1a,25-dihydroxyvitamin D. Journal of Bone and Mineral Research 200520 1944-1950. (doi:10.1359/JBMR. 050718)

15 Razzaque MS, St-Arnaud R, Taguchi T \& Lanske B. FGF-23, vitamin D and calcification: the unholy triad. Nephrology, Dialysis, Transplantation 200520 2032-2035. (doi:10.1093/ndt/gfh991)

16 Shaikh A, Berndt T \& Kumar R. Regulation of phosphate homeostasis by the phosphatonins and other novel mediators. Pediatric Nephrology 200823 1203-1210. (doi:10.1007/s00467008-0751-z)

17 Adams JS \& Hewison M. Update in vitamin D. Journal of Clinical Endocrinology and Metabolism 201095 471-478. (doi:10.1210/ jc.2009-1773) 
18 Jones G. Pharmacokinetics of vitamin D toxicity. American Journal of Clinical Nutrition $2008 \mathbf{8 8}$ (Supplement) 582S-586S.

19 Bagga A, Bajpai A \& Menon S. Approach to renal tubular disorders. Indian Journal of Pediatrics 200572 771-776. (doi:10.1007/ BF02734150)

20 Kolek AI, Hines ER, Jones MD, LeSeueur LK, Lipko MA, Kiela PR, Collins JF, Haussler ML \& Ghishan FK. 1 $\propto, 25$-hydroxyvitamin D3 upregulates FGF23 gene expression in bone: the final link in a renal-gastrointestinal-skeletal axis that controls phosphate transport. American Journal of Physiology. Gastrointestinal and Liver Physiology 2005289 G1036-G1042. (doi:10.1152/ajpgi. 00243.2005)

21 Mirams M, Robinson BG, Mason RS \& Nelson AE. Bone as a source of FGF23: regulation by phosphate (?) Bone $2004351192-1199$. (doi:10.1016/j.bone.2004.06.014)

22 Krajisnik T, Björklund P, Marsell R, Ljunggren Ö, Akerström G, Jonsson KB, Westin G \& Larsson TE. Fibroblast growth factor 23 regulates parathyroid hormone and $1 \alpha$-hydroxylase expression in cultured bovine parathyroid cells. Journal of Endocrinology 2007 195 125-131. (doi:10.1677/JOE-07-0267)
23 Komaba H \& Fukagawa M. FGF23-parathyroid interaction: implications in chronic kidney disease. Kidney International 2010 77 292-298. (doi:10.1038/ki.2009.466)

24 Kawata T, Imanishi Y, Kobayashi K, Miki T, Arnold A, Inaba M \& Nishizawa Y. Parathyroid hormone regulates fibroblast growth factor-23 in a mouse model of primary hyperparathyroidism. Journal of the American Society of Nephrology 200718 2683-2688. (doi:10.1681/ASN.2006070783)

25 Allen SC \& Raut S. Biochemical recovery time scales in elderly patients with osteomalacia. Journal of the Royal Society of Medicine 200497 527-530. (doi:10.1258/jrsm.97.11.527)

26 Imel EA, DiMeglio LA, Hui SL, Carpenter TO \& Econs MJ. Treatment of X-linked hypophosphatemia with calcitriol and phosphate increases circulating FGF23 concentrations. Journal of Clinical Endocrinology and Metabolism 201095 1846-1850. (doi:10.1210/jc.2009-1671)

Received 1 August 2010

Accepted 23 August 2010 